\title{
Rereading of To the Lighthouse From the Perspective of Narratology
}

\author{
LI Xiao-hua \\ Quzhou University, Quzhou, China
}

\begin{abstract}
To the Lighthouse is one of the masterpieces of Virginia Wolf, a well-known British stream-consciousness writer. It receives common favorable comments and recommendation from literary critics for the unique narrative techniques and writing style. This novel is to be interpreted herein from three aspects: narrative time, narrative perspective, and binary opposition under the temporal and space framework, for the purpose of exploring its deep structure and narrative features.
\end{abstract}

Keywords: To the Lighthouse, narrative time, narrative perspective, binary opposition

\section{Introduction}

Virginia Wolf, a well-known British stream-consciousness writer, plays a decisive role in British literary history with her great contribution to the development of British modern novels. She is honored as "the best female writer of the 20th century". To the Lighthouse is considered as her best work by many critics, reflecting her successful exploration and creativity in the narration of modern novels. The paper is to interpret the novel from three aspects: narrative time, narrative perspective, and binary opposition under the temporal and space framework. Penetrating the words, it is to explore the deep structure and narrative features and reveal the deep connotation and artistic charm behind the novel, and meanwhile probe into how the author expresses her thought of binary opposition in the work.

\section{Narrative Time}

Time is an indispensable factor in any narrative work. It can be categorized into two kinds, namely, the story time and the narrative time. The latter is usually the product of the author's handling of story time. According to the study of Genette (1980), study of the time order of narrative is actually comparing the marshalling sequence of time or time quantum in narrative discourse with that in the story. When the narrative time tallies with the story time, it is called "clockwise time-order" and otherwise, called "counter-clockwise time-order". "The traditional narrative works, influenced by the Greek aesthetic thought of 'simulation and reconstructing', tend to focus on the description and embodiment of real life so as to give the readers a real feeling" (TAI, 2002, p. 48). Most of them adopt a linear narrative mode and develop the story in clockwise time-order, which is very simple. From the beginning of 20th century, the newly-emerged modern novels started to cast off the past linear narrative mode

LI Xiao-hua, assistant, M.A., College of Foreign Languages, Quzhou University. 
and advocated implementation of free and flexible narrative mode, such as extension, shortening, omission, prolepsis, etc. To the Lighthouse is a good embodiment of such claims, showing Virginia Wolf's contribution and innovation in the aspect.

To the Lighthouse is divided into three parts. The first part Window mainly deals with the all kinds of matters that happened on the afternoon and evening when the Ramsays and their friends came to the coastal villa for vacation. The second part Time Fleeting starts from the bed time of the main characters and then tells the main events in the following 10 years. The third part The Lighthouse mainly talks about Mr. Ramsay with his children going to the lighthouse. From the Ramsays' gathering in the coastal villa to their visit to the lighthouse, there is a time span of 10 years. But the time division, under the writer's pen, is not tantamount as the author purposefully extended and shortened some time tantrums. Some parts are just briefly introduced and even deleted. The first part accounts for over a half space of the novel, which, however, is only a span of an afternoon and an evening. The narrative time of the second part spans 10 years, which is just briefly introduced with a short and lyric prose that may take up less than one tenth of the space of the novel. But some necessary information is added in the part, for example, Mrs. Ramsay passed away, Prew died of dystocia, Andrew laid down his life in war, and poet Mccauley won a great reputation which Mr. Ramsay lacked. The third part The Lighthouse is set in a morning, which however occupies a large space, slightly less than the first part. The three parts illustrat such a structure of "Long-Short-Long" in space but also a structure of "Short-Long-Short" in time span. These two structures form a good opposition and are well interweaved with each to present a kind of harmony. Virginia Wolf ever used the sign " $\mathrm{H}$ " in her note to allude such a structure. The first part and the third part are divided by the second part which plays as a connector between the other two parts. Such a structure presents a beauty of symmetry and brings readers a visual shock.

In the first part and the third part, the story time is very short. The story in the first part is set only in an afternoon and an evening while the third part only in a morning. In a slow narrative pace, the author continuously turns the time back to the past through the characters' retrospection. That is to say, in the natural flowing of real-life time, the past time is repeatedly inserted by the characters' mental activities. Thus the time quantum is so largely expanded that it overpasses 10 years. For example, in the first part, Mrs. Ramsay recalled her connections with the Mannings over 20 years ago, which in turn set the narrative time directly back to 20 years ago under the objective time framework. In the third part, Lily's mind kept flashing back and forth between the present and the past, which made the narrative time do the same. Sometimes the time change has no obvious markers. For instance, the section of Tansley's accompanying Mrs. Ramsay into the city seems to be written in the real time, which, however, is just Mrs' Ramsay's imagination when Tansley insisted on not going to the city the next day. The second part adopts a linear narrative mode and a very stable narrative pace without the insertion of different characters' mental activities. "Instead, the author uses her own language to record the pure five senses and describes her impression on the objective world" (QU, 2009, p. 8). It is just like a person's consciousness flowing, which is the typical feature of the stream consciousness novel.

The unique narrative time of the novel gives prominence to the author's innovation in the narration of novels. The time of real life and the time of the past are linked together through the characters' mental activities, which makes the textual structure full of flexibility. The readers can have a better understanding of the characters in the time change and spark a deep thinking of the meaning of life in the fleeting time. 


\section{Narrative Perspective}

"Narrative perspective, also called focalization, refers to the relationship between the narrator and the story" (SHEN, 2004, p. 53). Ever since Lubbock (1921) first used the term "perspective", narrative perspective has then become a hot issue in the narrative study circle. There are many researches about narrative perspective, among which French scholar Genette's study is most commonly considered authoritative. He used the term "focalization" and categorized it into three kinds: zero focalization, internal focalization, and external focalization. Zero focalization, also called omniscient perspective, means the author employs a kind of godlike perspective, which can make comprehensive narration. It can not only forsee the characters' future but also their past and can not only describe the characters' movement but also penetrate characters' mental world. Internal perspective means narration is made from the eye of certain character, through which the readers can beware of the situations and events related to the story. Internal focalization includes fixed internal focalization, convertible internal focalization, and multi-internal focalization. External focalization means the narration is made from the perspective of an outsider, who only describes others' movements, facial expressions, postures, etc., and no mental activities are involved. "The narrator, only acting as a camera, will not make any introduction with the author when it comes to the connotation and purpose of the video. They await the readers to comprehend by themselves" (JIANG, 2012, p. 65).

There is an omniscient narrator in To the Lighthouse who describes the whole story standing at a paramount position. He has wide enough vision to go into different characters' deep hearts and unearth their all kinds of mental states and even can dive into characters' sub-consciousness to find something unknown to themselves. They are just like gods, who know everything and whose vision point can shift optionally and step over any temporal or space obstacle. The focus point obviously in the story is shifted between different characters and scenes. The novel is narrated from the perspective of third person so as to keep distance between the reader and the characters of the work, which in result enables the readers to have enough wide vision. At the beginning of the first part, the omniscient narrator is tactfully exposed to the readers. We can see from the following:

Since he belonged, even at the age of six, to that great clan which cannot keep this feeling separate from that, but must let future prospects, with their joys and sorrows, cloud what is actually at hand, since to such people even in earliest childhood any turn in the wheel of sensation has the power to crystallise and transfix the moment upon which its gloom or radiance rests... (Virginia, 1989, p. 1)

This is the first scene of the story where there are only Mrs. Ramsay and James. Obviously, the description is not from Mrs. Ramsay but from the nearby omniscient narrator. He can dive into James' deep heart, unearth his thoughts and emotions, and then give comments from certain standpoint. Such comments are complete mastery of characters' consciousness, which enables the readers to beware of the characters' true feeling and mental states in reading so that they can better understand the gist and connotation of the novel.

According to German Narratology scholar F. K. Stanzel (1984, p. 89), given the factual purpose, the omniscient narrator cannot appear all the time in the whole story in any novel. His vision will sooner or later be confined or will temporarily lose the final direction to the characters or events. It is also the same case in To the Lighthouse. 
Apart from the omniscient narrative perspective, the novel also uses multiple internal focalization. When the novel develops somewhere, the omniscient narrator's perspective is confined, then the author moves to the backstage and shift the focus to the characters of the novel. It is not fixed on certain character but shifted between different characters according to the necessity of the plot and the narration. For example, based on the omniscient narrator's perspective, the first part employs Mrs. Ramsay's perspective, through which different characters come on the stage, first James, second Mr. Ramsay, then Tansley and also through which we have some understanding of the characters. From Ramsay's perspective, we see Lily whom the focus is then shifted to. With the appearance of Banks, the focus is transferred again. Through Banks' perspective, we get to know more about the Ramsay family. For example, the ever kind and simple Mr. Ramsay turns rigorous, numb, and rude; James is cruel and Andrew is just. Then the perspective is moved again to Mrs. Ramsay, through whom James, Mr. Ramsay, and Tansley present a more well-rounded image and some figures like Carmichael also show at the scene. The plot develops with such changes of perspectives. The second part of the novel adopts an omniscient narrator's perspective, highlighting nobody's discourse but only presenting the main information of the part in a prosaic language with the flow of the author's consciousness, i.e., Mrs. Ramsay passed away, Prue died of dystocia, Andrew sacrificed in the war, and poet Carmichael accomplished both success and fame. The third part of the novel adopts the same narrative techniques as the first part, however, due to the absence of some characters, the multiple internal focalizations and their changes in the part are much less than that in the first part.

Among the big perspective conversions, there are also some small ones, here we for the time being call them secondary perspective conversion, referring to some small perspective adjustment in the narration.

She was trying to get these tiresome stockings finished to send to Sorley's little boy tomorrow, said Mrs Ramsay.

There wasn't the slightest possible chance that they could go to the Lighthouse tomorrow, Mr Ramsay snapped out irascibly.

How did he know? She asked. The wind often changed. (Virginia, 1989, p. 32)

The first statement is made from Mrs. Ramsay's point of view, reflecting her expectation of next day. The second statement shifts the focus to Mr. Ramsay, actually reflecting his intervention of his wife and children's visit to the lighthouse. The third statement shifts the focus back to Mrs. Ramsay, reflecting her discontent at hearing her husband's discouragement and also reflecting their inharmonious relationship.

We can see the author skillfully combined zero focalization and multi-internal focalization to create a perfect transition between different parts. During the changes of focalizations, the readers sometimes can overlook the whole view of the novel and sometimes can dive into characters' inner world and feel their mental changes so that they can have a full understanding of not only the characters' images but also the collision of different characters' thoughts.

\section{The Binary Opposition in the Time and Space Scope}

Many narratologists tend to focus on the narrative perspective, narrative structure, and narrative logistics, but pay undue attention to the time and space structure in the novel. After reading through the novel, we can find inside there is a binary opposition structure, through which a metaphorical connotation is displayed to express the author's life attitude and pursuit. 
The first part of the novel starts from six o'clock of an afternoon that mainly tells about Mrs. Ramsay's discussion about their visit to the lighthouse the next day, plus the things that happened later. The ending time is the midnight after the banquet. Following the first part, the second part Time Fleeting starts from the bed time of the main characters and then tells the main events in the following 10 years, which is told only at a night. It ends with Lily's wakeup at the sunrise. The third part is only set at a morning which starts from Lily's ready to eat breakfast and ends with Mr. Ramsay's making the ascent to the lighthouse and Lily's finishing her painting. Here the temporal arrangement can be displayed with day and night. The first part moves from the afternoon to the evening, which can be signified as day—night. The second part is set at an evening, so that we can signify it as night. The third part is based on a morning so that we signify it as day. Thus the temporal structure of the whole novel can be expressed as: day—night—night—day. In the novel, day and night, being kind of sign, have rich metaphorical connotation, which we will continue to discuss below.

In the novel, there is a geographical transfer, in other words, space transfer. The Ramsays came to the seaside villa for vacations, but their destination is actually the lighthouse. The seaside villa appears in perfect order under Mrs. Ramsay' watch, and gathers many guests. The occasionally held parties further boost the relationship between each and spread around the warmth that find trace back to Mrs. Ramsay. However, beneath the lip-deep warmth is a sort of incoming decline and darkness. The candle light in the house is temporary and will go out lastly. The kind of lightness cannot last long and will annihilate in the darkness. Such a connotation is well displayed through the images and makes a foreshadowing for the following plot: the family goes declining, relatives and friends have to separate from each. If indicated by light and dark, the change can be shown as: light—dark. With the time elapsing, the previous harmonious state is gone and the second part is filled with darkness, chaos, and death. In the third part, 10 years later, the Ramsays regathered at the seaside villa which had already turned shabby, dark, and humid. So we can use dark to represent the second part. What remained the same all the time is the lighthouse, though located afar in the sea and in the hostile environment, still indicating directions for the ships on sea, which turns into a kind of eternal light, a human light pursued by Mrs. Ramsay. Their visit to the lighthouse in the third part is from dark to light. Therefore, the space transfer is actually a transfer of light pursuit by the Ramsays. Then the space structure of the whole novel is like this: light—dark—dark—light.

Daylight metaphorically refers to sunshine while night to darkness. It means the deep structures of time and space are the same and are a kind of perfect unity. Sunshine and darkness is a binary structure, which is inlaid through the whole story, reflecting the author's binary thought of darkness and lightness. Specifically, the author seeks lightness but is intruded and expelled by darkness. However, through the persistent efforts, human will eventually get rid of darkness and regain lightness.

\section{Conclusion}

Through the analysis in the paper, we can see Virginia Wolf's ardent innovation based on the critical inheriting of the predecessors' narrative skills. It makes the novel a hard-won masterpiece with its unique narrative skills. Meanwhile, the author's binary opposition thought is perfectly inlaid in the structure, unfolding before the eyes the author's attitude of winning beautiful life and conquering dark reality. 


\section{References}

Genette, G. (1980). Narrative discourse. Ithaca: Cornell UP.

JIANG, H. X. (2012). A narratological reading of David Loges' Changing Places. Contemporary Foreign Literature, 2, 65.

Lubbock, P. (1921). The craft of fiction. London: Jonathan Cape.

SHEN, D. (2004). Point of view. Foreign Literature, 3, 53.

Stanzel, F. K. (1984). A theory of narrative. (C. Goedsche, Trans.). Cambridge: Cambridge Up.

TAI, B. (2002). On the narrative structures and functions of The Great Gatsby. Jiangxi Social Science, 8, 48.

Virginia W. (1989). To the lighthouse. New York: Harcourt Brace Jovanovich.

Virginia W. (2009). To the lighthouse. (S. J. QU, Trans.). Shanghai: Shanghai Translation Publishing House. 